\title{
Tuning of NiSi/Si Schottky barrier heights by sulfur segregation during Ni silicidation
}

\author{
Q. T. Zhao \\ Institut für Schichten und Grenzfächen (ISG1-IT), and Center of Nanoelectronic Systems for Information \\ Technology (CNI), Forschungszentrum Jülich, 52425 Jülich, Germany \\ U. Breuer \\ Zentralabteilung für Chemische Analysen (ZCH), Forschungszentrum Jülich, 52425 Jülich, Germany \\ E. Rije, St. Lenk, and S. Mantl \\ Institut für Schichten und Grenzfächen (ISG1-IT), and Center of Nanoelectronic Systems for Information \\ Technology (CNI), Forschungszentrum Jülich, 52425 Jülich, Germany
}

(Received 27 September 2004; accepted 14 December 2004; published online 2 February 2005)

The Schottky barrier height (SBH) of NiSi on $\mathrm{Si}(100)$ was tuned in a controlled manner by the segregation of sulfur $(\mathrm{S})$ to the silicide/silicon interface. $\mathrm{S}$ was implanted into silicon prior to silicidation. During subsequent Ni silicidation, the segregation of $\mathrm{S}$ at the $\mathrm{NiSi} / \mathrm{Si}$ interface leads to the change of the SBH. The SBH of NiSi decreased gradually on $n$-Si(100) from $0.65 \mathrm{eV}$ to $0.07 \mathrm{eV}$ and increased correspondingly on $p$-Si(100). () 2005 American Institute of Physics. [DOI: $10.1063 / 1.1863442$ ]

Self-aligned silicidation is one of the key technologies in the state-of-art complementary metal-oxide-semiconductor (CMOS) process to make Ohmic or Schottky contacts at source/drain and gate. Amongst of them, NiSi silicide has emerged as a leading choice in Si nanometer electronics due to its low resistivity and high scalability. Recently, Schottky barrier source/drain metal-oxide-semiconductor field-effect transistors (MOSFETs) have been receiving a lot of attention because of the lower parasitic series resistance at source/ drain, possible zero junction depth and simpler fabrication process. ${ }^{1-4}$ However, for a typical Schottky barrier (SB) MOSFET, the on-current is limited by the tunneling through the Schottky barrier at the source. If a very low or a negative SBH could be realized, the on-current of SB-MOSFET could be increased substantially. ${ }^{4} \mathrm{NiSi}$ has an experimental SBH of $0.65 \mathrm{eV}$ on $n-\mathrm{Si}(100)$. This high $\mathrm{SBH}$ value hinders the application of NiSi in SB-MOSFETs. If we can lower the SBH of silicides to very low value, the device exhibits the same intrinsic performance as conventional MOSFET but also benefits from the advantages of SB-MOSFETs mentioned above.

In an ideal metal-semiconductor system the SchottkyMott theory suggests that the $\operatorname{SBH}\left(\Phi_{B}\right)$ is simply determined by the difference between the work function of the metal $\left(\phi_{M}\right)$ and the electron affinity of the semiconductor $\left(\chi_{S}\right)\left(\Phi_{B}=\phi_{M}-\chi_{S}\right){ }^{5}$ In practice, however, the presence of interface states leads to the SBH being less dependent on the metal work function. Dangling bonds at the semiconductor surface can be eliminated by valence-mending adsorbates. ${ }^{6} \mathrm{~S}$ and $\mathrm{Se}$ are two possible valence-mending candidates for the $\mathrm{Si}(100)$ surface. ${ }^{6}$ Lacharme et $a l .{ }^{7}$ reported that surface states on $\mathrm{Si}$ can be removed by $\mathrm{S}$ exposure at room temperature. Tao et $a l^{8-10}$ have used a monolayer of Se to eliminate the surface states on the $\mathrm{Si}(001)$ surface by terminating dangling bond and relaxing strained bonds. Pure metals, like $\mathrm{Mg}, \mathrm{Al}$, $\mathrm{Cr}$, and $\mathrm{Ti}$, on Se-passivated $n$-Si(001) showed very low and even negative SBH values which can be predicted by the Schottky-Mott theory. ${ }^{8-10}$ However, deposition of these ele- ments seems inappropriate for silicide contacts on $\mathrm{Si}$ due to the suppression of silicide formation. ${ }^{10}$ In order to benefit from advantages of silicides in state-of-art MOSFET technology, methods to tune the SBH of silicides on $\mathrm{Si}$ are required. In this paper we show an effective method to tune the SBH value of NiSi on both $n$ - and $p$-type $\mathrm{Si}(100)$. A small dose of $\mathrm{S}$ ions was implanted into Si before Ni deposition. During subsequent $\mathrm{Ni}$ silicidation, the segregation of $\mathrm{S}$ at the $\mathrm{NiSi} / \mathrm{Si}$ interface tunes the SBH.

$n$-type $\mathrm{Si}(100)$ with a resistivity of $2.5-8.5 \Omega \mathrm{cm}$, and $p$-type $\mathrm{Si}(100)$ with a resistivity of $7-21 \Omega \mathrm{cm}$ were used in the experiments. $250 \mathrm{~nm}$ thermal $\mathrm{SiO}_{2}$ was grown by wet thermal oxidation. After removal of the $\mathrm{SiO}_{2}$ on the backside by HF wet etching, $\mathrm{P}$ and $\mathrm{B}$ with a dose of $3 \times 10^{15} / \mathrm{cm}^{2}$ were implanted into the backside of $n-\mathrm{Si}(100)$ and $p$ $-\mathrm{Si}(100)$, respectively. The backside dopants were activated by rapid thermal annealing (RTA) in $\mathrm{N}_{2}$ at a temperature of $1050{ }^{\circ} \mathrm{C}$. Schottky diode windows were opened by photolithography and dry-etching of the $\mathrm{SiO}_{2}$ layers on the front side. Then $\mathrm{S}$ ions at an energy of $15 \mathrm{keV}$ in a dose range from $1 \times 10^{13}$ to $2 \times 10^{14} / \mathrm{cm}^{2}$ were implanted into the exposed $\mathrm{Si}$ diode areas using photoresist as the implantation mask. After removal of the photoresist and standard cleaning of the S-implanted samples, the native oxide on the Schottky diode areas was removed by an HF-dip and subsequently a $30 \mathrm{~nm} \mathrm{Ni}$ and a $10 \mathrm{~nm} \mathrm{Ti}$ (cap) layer were deposited using e-beam evaporation at room temperature. Ni silicidation was carried out by RTA at $550{ }^{\circ} \mathrm{C}$ for $1 \mathrm{~min}$ in forming gas $\left(90 \% \mathrm{~N}_{2}+10 \% \mathrm{H}_{2}\right)$. The Ti cap-layer and unreacted $\mathrm{Ni}$ were removed using $\mathrm{H}_{2} \mathrm{SO}_{4}: \mathrm{H}_{2} \mathrm{O}_{2}$.

NiSi layers formed by RTA at $550{ }^{\circ} \mathrm{C}$ for 1 min with and without $\mathrm{S}$ implantation prior to $\mathrm{Ni}$ deposition were investigated using cross-sectional transmission microscope (XTEM). Figure 1 shows an XTEM image of the NiSi layer formed on a $\mathrm{Si}(100)$ substrate implanted with $\mathrm{S}^{+}$at an energy of $15 \mathrm{keV}$ with a dose of $2 \times 10^{14} \mathrm{~S} / \mathrm{cm}^{2}$ prior to Ni deposition. The NiSi layer has a thickness of $62 \mathrm{~nm}$ with a high uniformity. The sheet resistance is $2.7 \Omega$ /square measured 


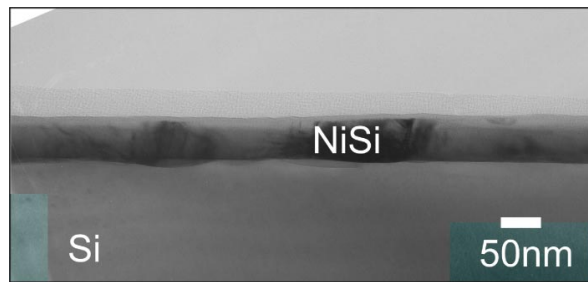

FIG. 1. XTEM image of a NiSi layer formed at $550{ }^{\circ} \mathrm{C}$ for $1 \mathrm{~min}$ on the $n$-Si(100) substrate implanted with $15 \mathrm{keV}, 2 \times 10^{14} \mathrm{~S}^{+} / \mathrm{cm}^{2}$ prior to $\mathrm{Ni}$ deposition.

by Van der Pauw measurements. It is known that Se deposition suppresses the silicidation, ${ }^{10}$ but we found that $\mathrm{S}$ implantation in a dose range from $1 \times 10^{13}$ to $2 \times 10^{14} / \mathrm{cm}^{2}$ does not affect the layer structure, layer thickness and the resistivity.

The Schottky diodes with and without S implantations were characterized using current-voltage $(I-V)$ measurements. The Ohmic contacts were made on the wafer backside using $200 \mathrm{~nm} \mathrm{Au}$. Figure 2 shows the $I-V$ characteristics of the $\mathrm{NiSi} / n$-Si(100) Schottky diodes. With increasing $\mathrm{S}$ dose, the SBH of NiSi decreases. At a dose of $2 \times 10^{4} \mathrm{~S} / \mathrm{cm}^{2}, \mathrm{NiSi}$ shows a perfect Ohmic contact to the $n$-Si(100). The SBH values on the $n-\mathrm{Si}(100)$ have been measured by activationenergy [current-temperature $(I-T)$ ] measurements. Figure 3 shows the plot of $I / T^{2}$ versus $1 / T$ at different forward bias $\left(V_{f}\right)$ for the sample with $15 \mathrm{keV} 2 \times 10^{14} \mathrm{~S} / \mathrm{cm}^{2}$ implantation. The SBH values are determined from the slopes of the curves. ${ }^{11}$ The slope of the curve in Fig. 3 is not constant. The

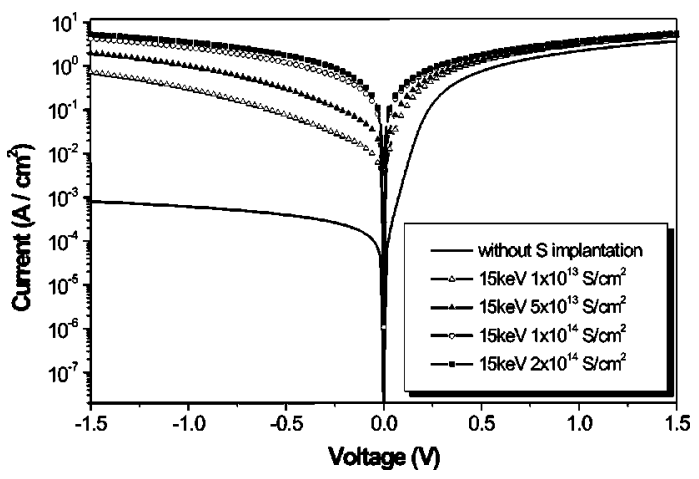

FIG. 2. $I-V$ characteristics of $\mathrm{NiSi} / n-\mathrm{Si}(100)$ Schottky diodes with and without $\mathrm{S}$ implantations.

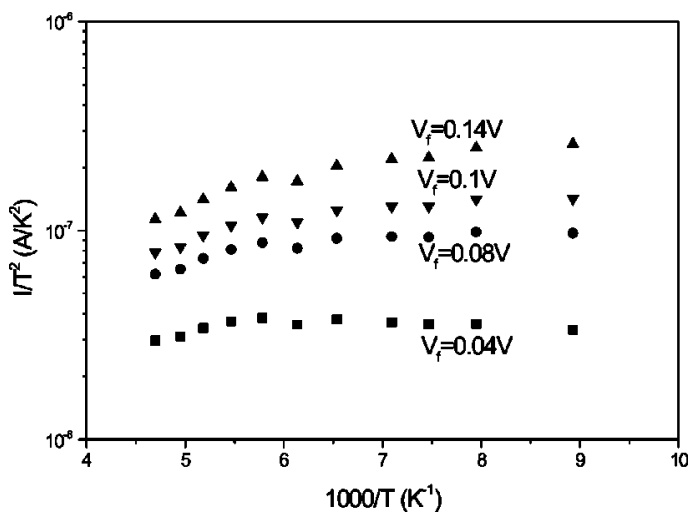

FIG. 3. Activation-energy measurements for the SBH determination of the NiSi diode formed on $n$-Si(100) implanted by $15 \mathrm{keV}, 2 \times 10^{14} \mathrm{~S}^{+} / \mathrm{cm}^{2}$

near the interface, considering the small solubility of S in Si
prior to Ni deposition.
Downloaded 21 Dec 2006 to 134.94.122.39. Redistribution subject to AIP license or copyright, see http://apl.aip.org/apl/copyright.jsp

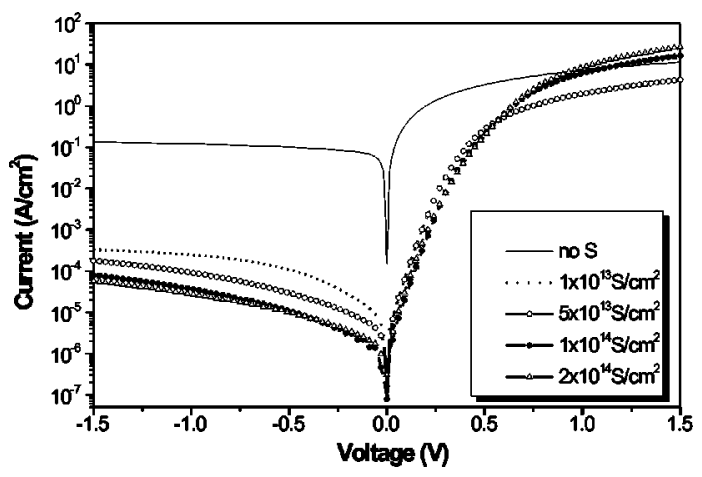

FIG. 4. $I-V$ characteristics of $\mathrm{NiSi} / p-\mathrm{Si}(100)$ Schottky diodes with and without $\mathrm{S}$ ion implantations.

reason is that when the thermal energy of the carriers is comparable to the $\mathrm{SBH}$, the barrier apparently disappears. In temperature data. ${ }^{9}$ The $\mathrm{SBH}$ values were in the range between $0.04 \mathrm{eV}$ to $0.09 \mathrm{eV}$ depending on the forward bias. The average $\mathrm{SBH}$ value is $0.07 \mathrm{eV}$ which is much lower than the conventional SBH of $0.65 \mathrm{eV}$ for NiSi on $n$-Si(100).

The effect of S implantation on the Schottky barrier of $\mathrm{NiSi}$ on $p-\mathrm{Si}(100)$ was also investigated. The $I-V$ characteristics of $\mathrm{NiSi} / p-\mathrm{Si}(100)$ Schottky diodes are shown in Fig. 4. Without $\mathrm{S}$ implantation, NiSi has an $\mathrm{SBH}$ value of $0.45 \mathrm{eV}$ on $p-\mathrm{Si}(100)$ extracted from the $I-V$ curve in Fig. 4 using thermal emission theory. ${ }^{11}$ The $\mathrm{SBH}$ values of $\mathrm{NiSi} / p$ - $\mathrm{Si}(100)$ increase with $\mathrm{S}$ implantation dose, which is indicated by the reduction of the reverse currents. A small dose of $1 \times 10^{13} \mathrm{~S} / \mathrm{cm}^{2}$ leads to a significant increase of the SBH to $0.68 \mathrm{eV}$. For a larger dose of $1 \times 10^{14} / \mathrm{cm}^{2}$, the $\mathrm{SBH}$ is $0.75 \mathrm{eV}$. Theoretically, the sum of the $\mathrm{SBH}$ on $n-\mathrm{Si}(100)$ $\left(\Phi_{b n}\right)$ and the $\mathrm{SBH}$ on $p-\operatorname{Si}(100)\left(\Phi_{b p}\right)$ equals approximately to the band gap of silicon $(\sim 1.1 \mathrm{eV})$. For samples without $\mathrm{S}$ implantation, $\Phi_{b n}+\Phi_{b p}=1.1 \mathrm{eV}$. But for samples with S implantation, $\Phi_{b n}+\Phi_{b p}<1.1 \mathrm{eV}$. A higher dose of S implantation results in a smaller $\Phi_{b n}+\Phi_{b p}$. Prokopyev et al. ${ }^{12}$ pointed out that when the SBH is large $(>0.7 \mathrm{eV})$, the extraction of SBH using $I-V$ methods is not correct because of minoritycarrier (electrons in $p$-Si) injections at metal contacts, and the errors increase with $\Phi_{b p}$. For a higher SBH, the leakage currents from the surface and edges of the diode also induce a large error. Therefore, other methods and Schottky diodes with guard-rings to reduce the leakage currents are necessary to measure the high SBH $(>0.7 \mathrm{eV})$ values.

In order to understand the effect of sulfur implantation on SBH, secondary-ion mass spectrometry (SIMS) was used to measure the $\mathrm{S}$ distribution after Ni silicidation, as shown in Fig. 5. The NiSi/Si interface is marked by the dashed line at the depth of $62 \mathrm{~nm}$. The mean depth of $15 \mathrm{eV} \mathrm{S}$ implantation in Si is $25 \mathrm{~nm}$, corresponding to a depth of $33 \mathrm{~nm}$ in $\mathrm{NiSi}$ after silicidation, which can be seen from the peaks at a depth of $33 \mathrm{~nm}$ in Fig. 5 for higher doses. The peak of the S distribution near the $\mathrm{NiSi} / \mathrm{Si}$ interface indicates the segregation of $\mathrm{S}$ during silicidation at $550{ }^{\circ} \mathrm{C}$. The concentration of the segregated $\mathrm{S}$ increases with the fluence of $\mathrm{S}$ implantation. After silicidation, the whole original S implanted region was converted to NiSi. Therefore, the $\mathrm{S}$ distribution near the $\mathrm{NiSi} / \mathrm{Si}$ interface is caused by segregation of $\mathrm{S}$ during silicidation. Predominantly, the $\mathrm{S}$ is found in the silicide and near the interface, considering the small solubility of $\mathrm{S}$ in $\mathrm{Si}$ AIP license or copyright, see http://apl.aip.org/apl/copyright.jsp this case, the SBH value can be determined using the low 


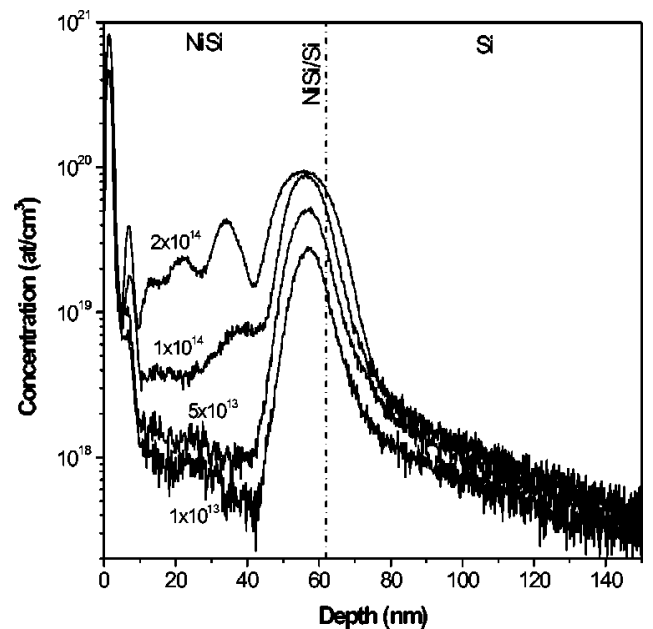

FIG. 5. SIMS depth profiles of $\mathrm{S}$ for various $\mathrm{S}$ fluences after Ni silicidation at $550{ }^{\circ} \mathrm{C}$.

$\left(<10^{15} \mathrm{~cm}^{-3}\right) .{ }^{13}$ The sluggish exponential decrease of the $\mathrm{S}$ depth profiles deeper in the $\mathrm{Si}$ substrate shown in Fig. 5 could be due to interface effects and the sensitivities of the SIMS method. Because of the low energy $\left(1 \mathrm{keV} \mathrm{Cs}^{+}\right)$of the sputtering ions, the "knock-on" effects by the ion beam during SIMS measurements do not influence the $\mathrm{S}$ distributions. Further investigations will be done to study the $\mathrm{S}$ diffusion in the $\mathrm{Si}$ substrate. The segregation of $\mathrm{S}$ at the NiSi/Si(100) interface leads to the change of SBH. Figure 6 shows the $\mathrm{SBH}$ values of $\mathrm{NiSi}$ on $n-\mathrm{Si}(100)$ as a function of the $\mathrm{S}$ concentration at the interface. The SBH drops very quickly from the original $0.65 \mathrm{eV}$ to $0.34 \mathrm{eV}$ at a $\mathrm{S}$ concentration of $1.38 \times 10^{19} / \mathrm{cm}^{3}$, and then decreases approximately linearly with the $\mathrm{S}$ concentration at the interface.

The segregation of $\mathrm{S}$ at the $\mathrm{NiSi} / \mathrm{Si}(100)$ interface leads to a large change of the SBH and allows SBH tuning in a wide range. A model of the $\mathrm{S}$ passivation of the $\mathrm{Si}$ surface has been proposed by Saiz-Pardo et al. ${ }^{14}$ They showed that the effect of S-passivation is to modify the Fermi level position by moving it in the higher (lower binding) energy direction, leading to an Ohmic contact with the Fermi level

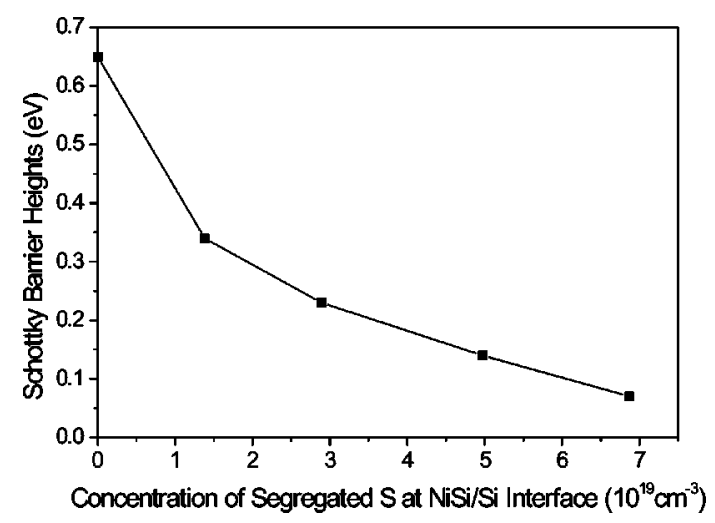

FIG. 6. SBH values of $\mathrm{NiSi}$ on $n-\mathrm{Si}(100)$ as a function of the concentration of the $\mathrm{S}$ atoms segregated at the $\mathrm{NiSi} / n-\mathrm{Si}(100)$ interface. pinned right at the semiconductor conduction band minimum. The Fermi level shift is basically due to the interaction between the metal and the local density of the states associated with the passivating layer. ${ }^{13}$ After passivation of the $\mathrm{Si}$ surface by a Se monolayer, the $\mathrm{SBH}$ values of $\mathrm{Ti}, \mathrm{Cr}, \mathrm{Al}$, and $\mathrm{Mg}$ on Se passivated Si reached the values of the SchottkyMott theory. However, in our present work, the lowest SBH value of $\mathrm{NiSi}$ on $n$-Si(100) is much smaller than the Schottky-Mott theoretical value if one assumes a work function of NiSi of $4.68 \mathrm{eV} .{ }^{15}$ During NiSi formation by solidreaction of $\mathrm{Ni}$ with $\mathrm{Si}$ substrate, chemical bonds are formed at the NiSi/Si interface. These interface bonds influence the $\mathrm{SBH}$ value. We suggest that the tuning of NiSi SBH values by $\mathrm{S}$ segregation at interfaces is mainly due to two effects. First, the formation of chemical bonds between $\mathrm{S}$ and $\mathrm{NiSi}$ changes the work function of the NiSi, and second, the segregation of $\mathrm{S}$ at interfaces form a dipole layer at the $\mathrm{NiSi} / \mathrm{Si}$ interface. Further investigations are needed to clarify the detailed mechanism. As compared to the deposition of a $\mathrm{Se}$ monolayer between the metal and Si to change the SBH of the metal, ${ }^{8-10}$ this method has several advantages. Selfaligned silicidation combined with $\mathrm{S}$ ion implantation can be easily used to fabricate nanometer MOSFETs. Diodes with different SBHs on one wafer can be made by the use of different ion fluences. Investigations using Se ion implantation and other silicides, and applications of this method in devices are in process.

In summary, a method to tune the Schottky barrier height of NiSi on $\mathrm{Si}(100)$ substrates by segregation of $\mathrm{S}$ was investigated. The $\mathrm{SBH}$ value of $\mathrm{NiSi}$ on $n$-Si(100) substrates decreases by increasing the dose of $\mathrm{S}$ implantation prior to $\mathrm{Ni}$ deposition. The $\mathrm{SBH}$ was reduced from $0.65 \mathrm{eV}$ to $0.07 \mathrm{eV}$ on $\mathrm{S}$ implanted $n$-Si(100), while the $\mathrm{SBH}$ on $p$-Si(100) increases by $\mathrm{S}$ implantation.

${ }^{1}$ J. Kedzierski, P. Xuan, E. Anderson, J. Boker, T. King, and C. Hu, IEDM Tech. Dig. 57 (2000).

${ }^{2}$ Q. T. Zhao, P. Kluth, S. Winnerl, and S. Mantl, Solid-State Electron. 47, 1183 (2003).

${ }^{3}$ C. Wang, J. P. Snyder, and J. R. Tucker, Appl. Phys. Lett. 74, 1174 (1999).

${ }^{4}$ J. Guo and M. Lundstrom, IEEE Trans. Electron Devices 49, 1897 (2002).

${ }^{5}$ R. T. Tung, Mater. Sci. Eng., R. 35, 1 (2001).

${ }^{6}$ E. Kaxiras, Phys. Rev. B 43, 6824 (1991).

${ }^{7}$ J. P. Lacharme, N. Benazzi, and C. A. S Benne, Surf. Sci. 433-435, 415 (1999).

${ }^{8}$ M. Tao, D. Udeshi, N. Basit, E. Maldonado, and W. P. Kirk, Appl. Phys. Lett. 82, 1559 (2003).

${ }^{9}$ M. Tao, S. Agarwal, D. Udeshi, N. Basit, E. Maldonado, and W. P. Kirk, Appl. Phys. Lett. 83, 2593 (2003).

${ }^{10}$ M. Tao, D. Udeshi, S. Agarwal, E. Maldonado, and W. P. Kirk, Solid-State Electron. 48, 335 (2004).

${ }^{11}$ S. M. Sze, Physics of Semiconductor Devices, 2nd ed. (Wiley, New York, 1981).

${ }^{12}$ A. I. Prokopyev and S. A. Mesheryakov, Measurement 33, 135 (2003).

${ }^{13}$ R. G. Wilson, J. Appl. Phys. 55, 3490 (1984).

${ }^{14}$ R. Saiz-Pardo, R. Pérez, F. J. García-Vidal, R. Whittle, and F. Flores, Surf. Sci. 426, 26 (1999).

${ }^{15}$ E. Bucher, S. Schulz, M. Ch. Lux-Steiner, P. Munz, U. Gubler, and F. Greuter, Appl. Phys. A: Solids Surf. 40, 71 (1986). 